
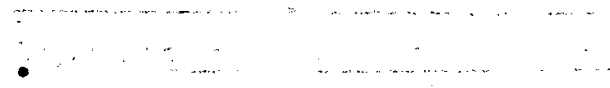

\section{INSTRUMENTATION FOR GRANITE TEST NO. 1}

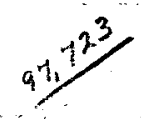

\author{
Bert R. Dennis \\ Robert M. Potter \\ Staff Members \\ Los Alamos Scientific Laboratory \\ of the University of California \\ Los Alamos, New Mexico 87544
}

\section{Conf- $740504-2$}

NOTICE

This report was prepared as an account of work sponsored by the United States Government. Neither the United States nor the United States Atomic Energy Commission, nor any of their employees, nor any of their corttractors, subcontractors, or their employees, makes any warranty, express or implied, or assumes any legal liability or responsibility for the accuracy, completeness or usefulness of any information, apparatus, product or process disclosed, or represents that its use would not infringe privately owned rights.
ABSTRACT

Initial measurements to evaluate the feasibility of extracting energy from hot-dry rock in Precambrian basement (granite) employing hydraulic-fracturing techniques was explored in the LASL Granite Test Hole No. 1. Following a series of hydrology experiments in the $785-\mathrm{m}(2575 \mathrm{ft})$ depth hole, preparations were made to instrument a series of hole-pressurization and hydraulic-fracturing experiments. The instrumentation was designed to measure breakdown pressure, crack-extension pressure, and shut-in pressure for each fracture and to determine principle tectonic stresses, breakdown stress for hydraulic fracturing, and leak-off rate for fracturing fluid.

\section{INTRODUCTION}

The Los Alamos Scientific Laboratory has initiated a program for the research and development of geothermal energy. The Jemez Mountains in north-central New Mexico have been selected for initial experiments in the development of a man-made geothermalenergy system. The region of the valies Caldera in the heart of the Jemez Mountains was the scene of volcanic activity as recently as 40,000 to 50,000 years ago. (1)

Preliminary investigations indicated that very hot rock exists at moderate depth throughout the area. To verify temperature extrapolations and to investigate directly the structure and properties of the Precambrian basement rock, Granite Test Hole-No. 1 (GT-1) was drilled on the west side of the Caldera to a depth of $785 \mathrm{~m}(2575 \mathrm{ft}) .(2)$

After drilling, hydrological tests were made on the hole. These tests confirmed the very-low mean permeability of the granite basement, and its ability to contain water at pressures up to 900 psi above hydrostatic: A straddle-type packer was used to isolate portions of the hole and to introduce hydraulic pressure to the borehole walls between the upper and lower parts of the packer.

\section{REQUIRED INSTRDEENTATION}

Following hydrology experiments in Granite Test Hole No. 1 , preparations were made to instrument a series of hole-pressurization and hydraulic-fracturing experiments. The instrumentation was designed to measure breakdown pressure of the rock, crack-extension pressure and shut-in pressures for each fracture and to determine principal tectonic stresses, breakdown stress for hydraulic fracturing and leak-off rate of the fracturing fluid. Two pressure measurements were to be recorded--the primary measurement being made downhole in the pressurized zone. As a backup, a second pressure transducer recorded fluid pressure in the borehole at the ground surface. The downhole pressure transducer was installed in the pipe string below a shut-off valve. This valve was designed to actuate at breakdown pressures thus preventing excessive post-breakdown crack growth. Sutice pressure would then be bled off until the shut-off valve equalized (at initial formation shut-in pressure) allowing crack extension to be controlled.

A three-component geophone was located on the downhole side of the bottom stracale packer immediatey below the pressurized region. The geophone package was designed to be mounted sererely to the bottom packer thus insuring merienical coupling into the openhole rock fumetion. The geophone would hopefully monito acoustic signals generated by the cracking events and help determine the feasibility ot mapping crack extensions employing triangustion techniques. The downhole geophon would also provide a time correlation for 20 ismic array deployed at the surface. Tha surface array would monitor seismic backound of the experimental area before and buing the fracturing experiments. It was hopeful that the close-in surface array nist detect an acoustic signal generated by the elastic strain-energy release that cccirs when the rock fractured. The detection of the acoustic signals from both the downhoic jackage and the surface array would possisly permit mapping of the hydraulic fracture as it grew. 


\section{DISCLAIMER}

This report was prepared as an account of work sponsored by an agency of the United States Government. Neither the United States Government nor any agency Thereof, nor any of their employees, makes any warranty, express or implied, or assumes any legal liability or responsibility for the accuracy, completeness, or usefulness of any information, apparatus, product, or process disclosed, or represents that its use would not infringe privately owned rights. Reference herein to any specific commercial product, process, or service by trade name, trademark, manufacturer, or otherwise does not necessarily constitute or imply its endorsement, recommendation, or favoring by the United States Government or any agency thereof. The views and opinions of authors expressed herein do not necessarily state or reflect those of the United States Government or any agency thereof. 


\section{DISCLAIMER}

Portions of this document may be illegible in electronic image products. Images are produced from the best available original document. 


\section{LIMITATIONS}

Several initial limitations concerning downhole instrumentation were anticipated and every effort was made to minimize foreseeable problems. The temperature in the zone of interest reached $100^{\circ} \mathrm{C}$. This temperature caused no serious threat to the transducers (the pressure gauge was rated at $148.9^{\circ} \mathrm{C}\left(300^{\circ} \mathrm{F}\right)$ and the geophones rated at $\left.148.9^{\circ} \mathrm{C}\left(300^{\circ} \mathrm{F}\right)\right)$ but could affect operation of any dowihole electronics employed to boost low level signals or drive long signal lines to the surface recording equipment. In view of more severe temperature Iimitations that would be encountered in future test holes, it was decided to employ electronics at the surface recording station. The electronic apparatus selected had been proven to adequately measure lowlevel signals over long-signal lines with excellent common-mode (noise) rejection and gain/linearity characteristics.

A second problem anticipated in the downhole measurements concerned the static head pressure of the hydraulic fluid that completely filled the hole. This resulted in the design of transducer housings, and all electrical connections, to withstand the head pressure to prevent water from intruding into the instrumentation cables. The pressure gauge was mounted on an offset sub assembly (Fig. 1) located just above the top straddle packer and below the shutoff valve seating nipple. Because its location imposed stringent size requirements, the transducer housing connector assembly had to be especially machined (Fig, 2).

\section{INSTRUMENTATION DATA}

The instrumentation cable used for downhole measurements was a high grade, low impedance, $16.2 \mathrm{ohms} / 305 \mathrm{~m}$ (16.2 ohms/1000 ft) cabie containing three individually-shielded twisted pair of 22-gauge copper stranded wire. The $z$-fold, mylar tape shield wrapped around each pair included a drain wire. A tough Marlastic 101 jacket housed the pairs and the downhole end was terminated with a molded and sealed marine connector. The overall outside diameter of this cable was $8 \mathrm{~mm}(5 / 16$ in.). The cable did not employ steel armour normally used in logging cable. Assuming the uncased hole to be perfectly straight, clearance after cable installation was only $3 \mathrm{~mm}(1 / 8 \mathrm{in.})$.

The cable was connected to the downhole instrument package at the surface and was reeled off as the hydraulic tubing was lowered into the hole. The cable was strapped to the tubing with steel hose clamps at selected intervals. The first $29.3 \mathrm{~m} 196$ ft) of downhole cable was inserted into flexible aluminum conduit for added protection against a casing shoe, which was known from previous logging runs to be protruding into the open portion of the hole. continuity checks were carefully made at a number of intervals during insertion to assure that the transducer and cable remained operation, since it was realized that a failure of the downhole instrumentation during insertion would cost an additional round trip of the tubing.

The downhole geophone package was threaded into a specially designed sub assembly inserted into the bottom packer to insure positive coupling with the surrounding rock formation. It was necessary to run the geophone cable up through the packer assembly and out of the tubing via a sealed feedthrough ( $F i g .3)$. It was also necessary, although undesirable, to splice the cable at the uphole side of this feed-through. Field splice kits employing a sealing epoxy and moulded boots proved successful.

A second triaxial geophone, identical to the downhole package, was mounted as a backup system at the surface some $30 \mathrm{~m}$ (85 $\mathrm{ft}$ ) south of the granite test hole by imbedding the instrument in the frozen ground.

Data acquisition and recording equipment was installed in a $6-\mathrm{m}(20-\mathrm{ft})$ by $2.4-\mathrm{m}$ (8ft) trailer located several meters from the wellhead. The data acquisition electronics included B \& F Model 2460 signal conditioners, Astrodata Model 886 wide-band differential amplifiers, an Ampex CP100 magnetictape recorder and an eight-channel Technirite 888 direct-write strip chart recorder. Auxillary equipment included two John Fluke Model $8300 \mathrm{~A}$ digital voltmeters, a Tektronix 556 dual beam oscilliscope and a systron Donner 8110 time-code generator (Fig. 4). The on-line strip-chart recorder was used primarily for initial small fracture experiments. Data were recorded on magnetic tape during the large "Halliburton" fractures.

\section{CHRONOLOGICAL ORDER OF EXPERIMENTS}

The series of chronological events summarized in this report will cover only those experiments in wich either downhole and/or surface electronis measurements were significant in determining the success (or failurel of the ydraulic fracture attempts. on February 23 , the downhole pressure transducer and sub-assmbly carrier was pressure checked at the surface to 206.7 bars $(3000$ psi) in 34.45 bass (500 psi) increments. The following day the transducer assembiy was mounted on the straddle-packer assembly and lowered into the hole in preparation for the first fracture experiment. The pressure transducer was checked about onethird of the way into the hole and found to be equilibrating to hydrostatic pressure. It was surmised that the additional machining of the gauga-housing connector allowed venting of the low gressure side of the 
transducer to the annulus hydrostatic pressure. The transducer was still usable to measure pressure above hydrostatic, 74.1 bars (1075 osi), which was suitable for pressurization measurements. Due to a ruptured seal on the straddle packer assembly, the experiment was aborted and the tubing pulled out of the hole. Careful examination of the instrumentation cable revealed several places where the steel cable clamps had caught on the casing wall during extraction and cut the jacket exposing bare conductors. The instrumentation cable was repaired and insulated wire clamps replaced the steel cable clamps to prevent further damage.

On Wednesday March 7, the first hydraulic fracture was made. During this experiment, the shut-off valve closed as intended but did not reopen after the pressure equalized. Attempts to extend crack growth were terminated. A second experiment attempt resulted again in the shut-off valve failing to open. Upon examination of the valve assembly, it was found that pollution of the hydraulic fluid, primarily with pipe dope, gummed up the valve causing the failure. However, pressure records from the fracture experiments revealed that no danger from back pressure was evident and the shut-off valve could be retired. This also meant that the downhole pressure measurement was not quite so necessary and, in view of continuing cable ruptures due to abrasions when tripping the tubing, it was decided to instrument the fluid pressure only at the surface.

Following four successful small fracture experiments, the scheduled downhole geophone tests were begun. The geophone package was threaded into the bottom packer assembly and the signal cable pulled through the sealed feed-through. The assembly was pressure checked at the surface to 103.4 bars (1500 psi). Once again, the timeconsuming task of strapping the signal cable to the tubing was undertaken and continuity checks were made several times while inserting the tubing string. The fracture zone was pumped up to a maximum of 70.1 bars (1018 psi) when the pressure began to fall off. The experiment was aborted and examination of the system revealed that the instrumentation cable had extruded through the feed-through, stripping the cable jacket and causing the leak. Due to the imposed time schedule to finish this series of experiments, downhole instrumentation was reluctantly abandoned.

Primary instrumentation for the remaining experiments consisted of the surface pressure gauge and the surface triaxial geophone that had been imbedded in the frozen ground. Two additional small fracture experiments were performed with no malfunctions and excellent results.
The straddle packer assembly was located in a zone where no pre-existing cemented rock fractures had been detected by core examinations. The chosen interval was centered at a depth of $745.2 \mathrm{~m}(2445 \mathrm{ft})$. The zone was pressurized to 60.6 bars ( 880 psi) and shut in to check for leaks. Pumping was resumed and the pressure level peaked out at 106.45 bars $(1545 \mathrm{psi})$. Figure 5 shows an oscillograph record reproduced from the magnetic tape recording. The record shows the surface pressure channel along with one horizontal geophone channel, $\mathrm{H} 2$, and the vertical geophone channel, V1. The pressure channel clearly shows the gauge shut-in areas during which time a Heise reading was made. No significant acoustic signals were detected. Figure 6 is a highspeed record of the same data showing the individual pump strokes on the pressure chamnel. Straight lines drawn through the slopes intersect at a pressure of 104.4 bars (1515 psi) which is in good agreement with the Heise readout. Figures 7 and 8 are oscillograph records of the repump experiment performed in the same zone to obtain a fracture extension pressure. This pressure was measured at 86.1 bars (1250 psi). Again no acoustic signals were detected. The records of the experiments performed on March 28 were chosen to exemplify the smail fracture events. A summary of breakdown and fracture extension pressures for the small fracture experiments is given in Table $I$.

\section{TABLE I}

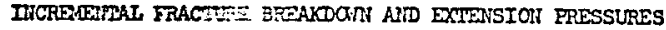

\begin{tabular}{|c|c|c|c|c|c|c|}
\hline \multirow[b]{2}{*}{ Date } & \multirow{2}{*}{$\begin{array}{c}\text { Depth } \\
\text { (meters) }\end{array}$} & \multirow[b]{2}{*}{80} & \multicolumn{2}{|c|}{ Ereakdown } & \multicolumn{2}{|c|}{ Extension } \\
\hline & & & bers & psi & bars & ps1 \\
\hline $3-7$ & 761.4 & $(-109)$ & 90.5 & (1320) & - & - \\
\hline $3-14$ & 772.7 & $(253)$ & $>151.6$ & $(>2200)$ & 72.3 & $\sim 1050$ \\
\hline $3-21$ & 752.3 & 253 & 95.1 & (1380) & 81.0 & 2175 \\
\hline $3-23$ & 776.3 & $(y+7)$ & 90.9 & (1320) & - & - \\
\hline $3-24$ & 740.4 & $\{2+29\}$ & 80.6 & (1270) & 69.9 & 1015 \\
\hline $3-27$ & 743.3 & $\$ 55$ & 117.3 & (1702) & 89.6 & 1330 \\
\hline $3-28$ & 745.2 & $(-9)$ & 104.0 & (1510) & $B<: .5$ & 1232 \\
\hline
\end{tabular}

The straddled, $\cdots$ for the fracture experiment on Marcs : contained at least four cemented fract: -3 . The straddled zones for the Marct: " and March 28 evperiments were fracture--... granite incervals before the hydraulic $:-s=s$ were performed.

On April 4, the alliburton equipment was located on site 00 attempt a large fracture in Granite Test sole 1. Some difficulty was encounteres in setting the packer assembly in the $50 \mathrm{n}$ hole rock formation. A fracture atteres mas made and a pressure of 151.6 bars (220 zii) was reached before aborting the $6=5:$. Later examination of the tape recor $=$ r.y reved a sizable acoustic signal (Fig. H) which confirmed indications that $a$ sacture did occur. Figure 10 is an expandicy record of the seismic 
signal showing compressional and shear components as recorded by the geophones.

On: the following day, April 5, a new packer assembly was installed in the open hole and a second attempt to create a large fracture was successful. The oscillograph record of this experiment shows a large acoustic signal resulting from the crack extension (Fig. 11). Compressional and shear wave components are again defined in the highspeed expansion of the data as shown in Fig. 12. The seismic event occurred approximately $6.2 \mathrm{sec}$ after pump shut-in at which time a refracted pressure wave was detected on the surface pressure gauge. A plot of the pressure wave showing the refracted wave is given in Fig. 13. Both a compressional and shear wave were detected at the geophone as evidenced by the two separate and distinct frequency components. The first component ( $P$ ) has a frequency of $16.8 \mathrm{~Hz}$ followed about $280 \mathrm{msec}$ later by a second component (S) with a frequency of $12.8 \mathrm{~Hz}$. Little if any information can be obtained from the amplitude of the acoustic signals since the natural frequency of the geophone $(2 \mathrm{~Hz})$ is somewhat above the measured frequency components. Detailed analysis of the seismic events recorded during this series of experiments is presented in the report "seismic and Fluid Pressure Response from a Series of Hydraulic Fractures in Granite." (3)

The surface array of seismic stations was unfortunately not in operation during the large fracture experiments. Correlation of fracture orientation and extension is therefore not possible from seismic information.
Data recorded from the surface array during the small fracture experiments show no detection of microseismic events.

\section{CONCLUSION}

The overall test results from the GT-1 hydraulic fracture experiments proved most successful. Plans are now operational to drill a second Granite Test Hole, GT-2, where more elaborate and extensive hydraulic fracturing experiments will be conducted at depths up to $1829 \mathrm{~m}(6000 \mathrm{ft})$ and temperatures approaching $200^{\circ} \mathrm{C}$. A downhole instrumentation package is being designed, independent of the hydraulic tubing. and capable of withstanding the severe environment. A surface array of seismometers and tiltmeters will be fielded to insure experimental data to determine the probability of mapping the fracture at large depths.

\section{REFERENCES}

1. Smith, M. C., "The Los Alamos Geothermal Energy Project," Los Alamos Scientific Laboratory internal report LA-UR-73-1029 (March 1973).

2. West, F. G., "Regional Geology and Geophysics of the Jemez Mountains," Los Alamos Scientific Laboratory report LA-5362-MS (Aug 1973).

3. Dennis, B. R. and Potter, R. M.,"Seismic and Fluid Pressure Response from a Series of Hydraulic Fractures in Granite," talk presented at the AGU Meeting in Washington, D. C., April 8-12, 1974. 
FIG. 5. PRESSURE AND GEOPHONE RECORDED DATA, GT-1, 3-28-73.

FIG, 6. BREAKDOWM PRESSURE, GT-1, 3-28-73. 
FIG. 7. REPUMP OF 3-28-73. 
FIG. 9. LARGE FRACTURE EXPERIMENT, HB-2, 4-4-73

FIG. 10, P AND S IIAVE, HB-2, 4!-4-73. 
FIG. 11. LARGE FRACTURE, HB-5, 4-5-73.

FI6. 12. $P$ ANI $S$ COMPONENTS, HB-5, 4-5-73. 
FIG. 13. REFRACTED PRESSURE HAVE. 


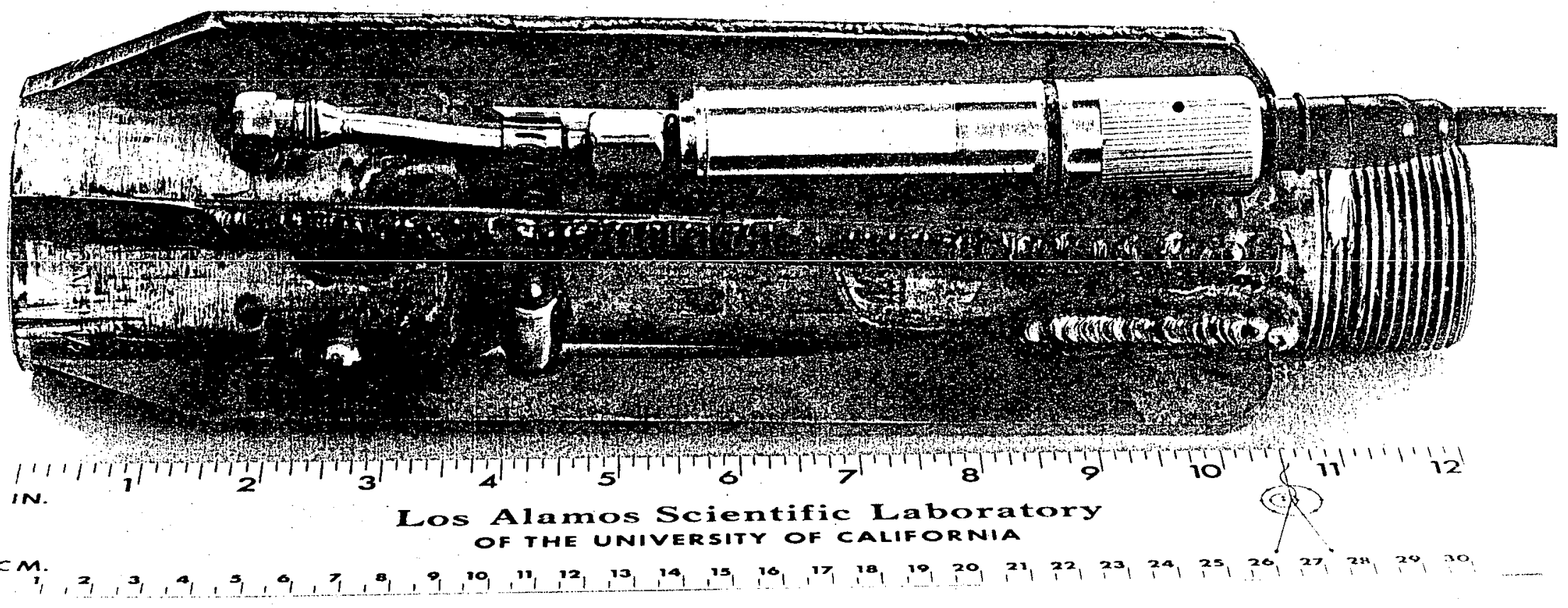

$\operatorname{sig} .1$. 


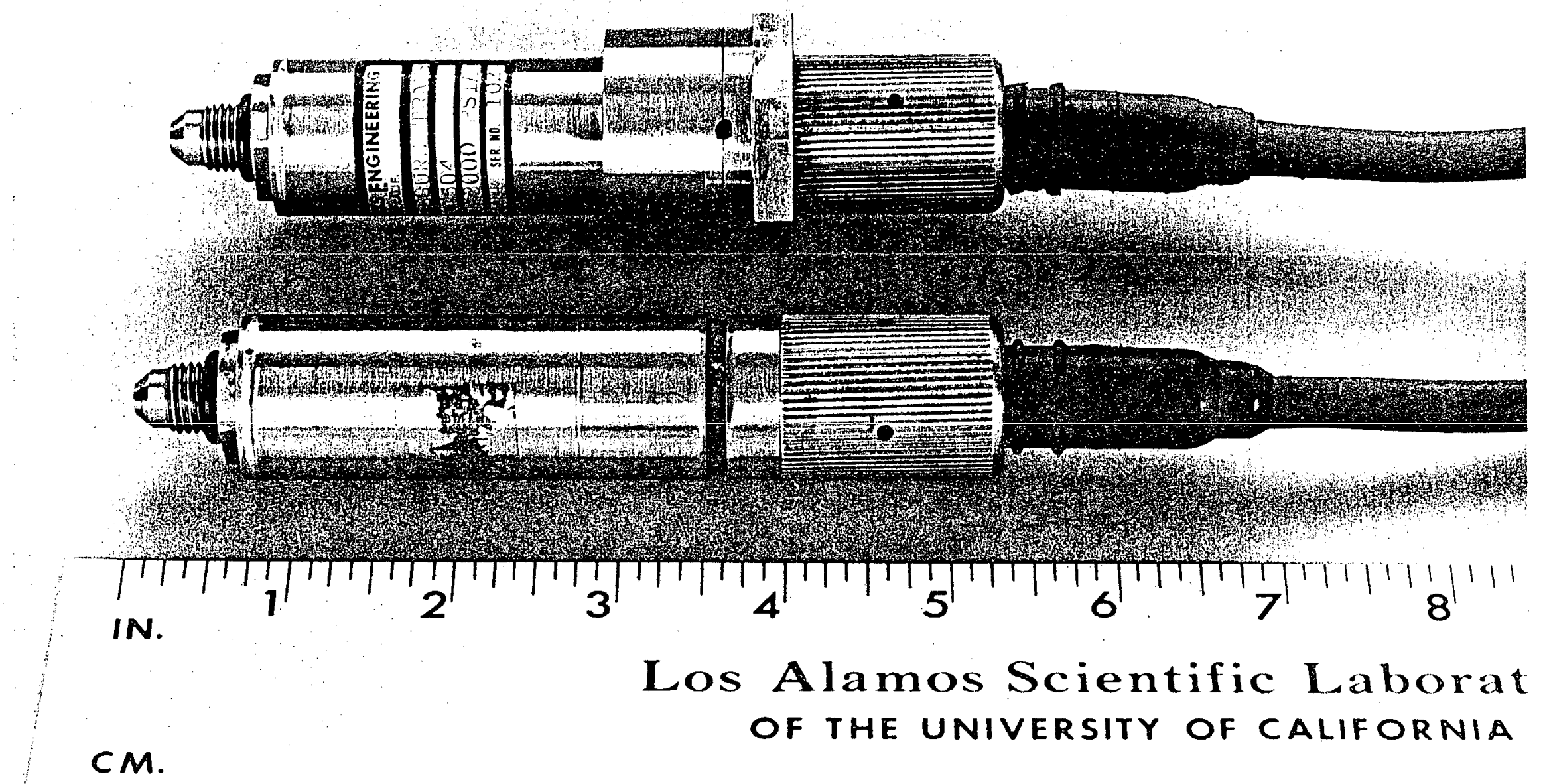

Bug. 2 . 


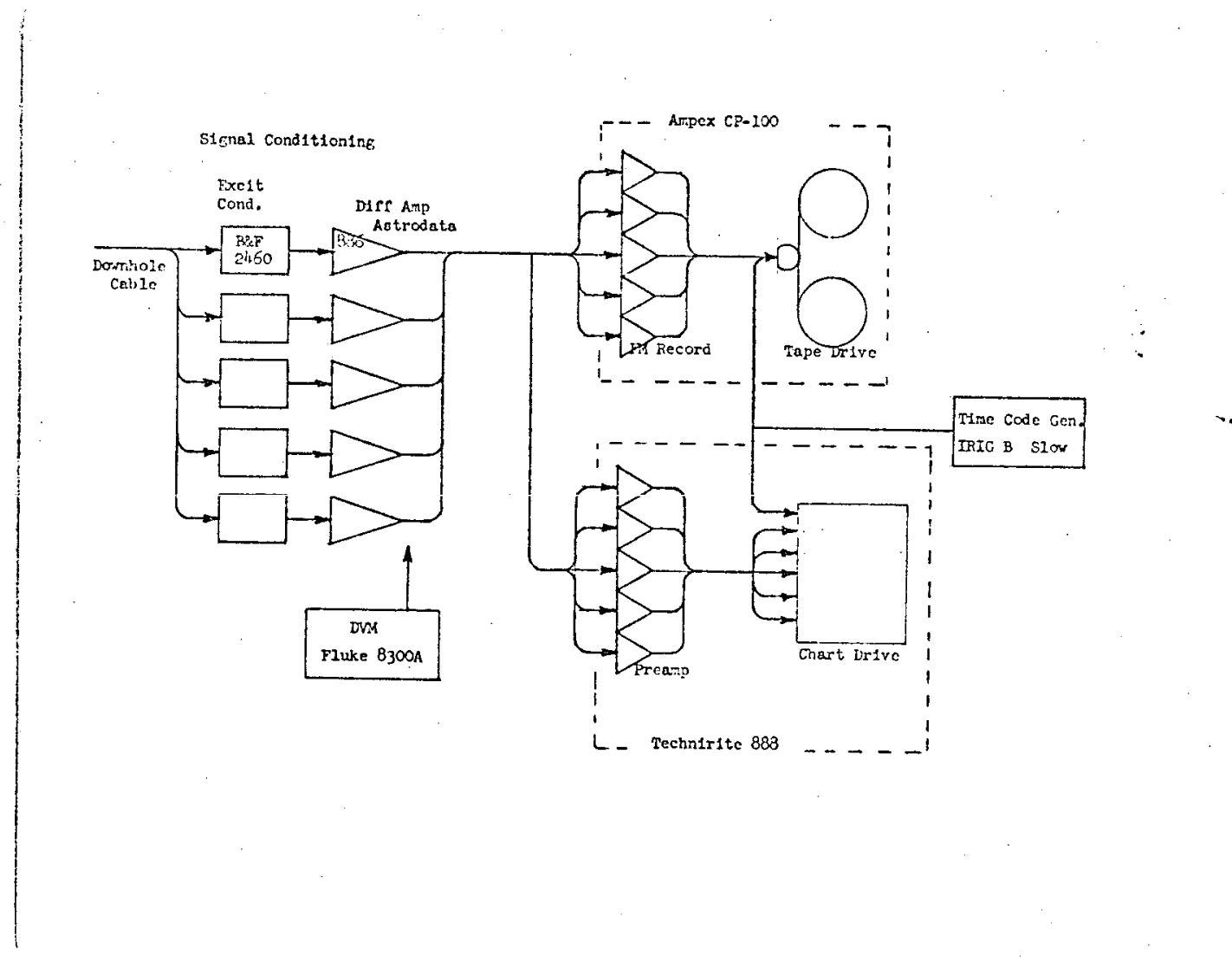




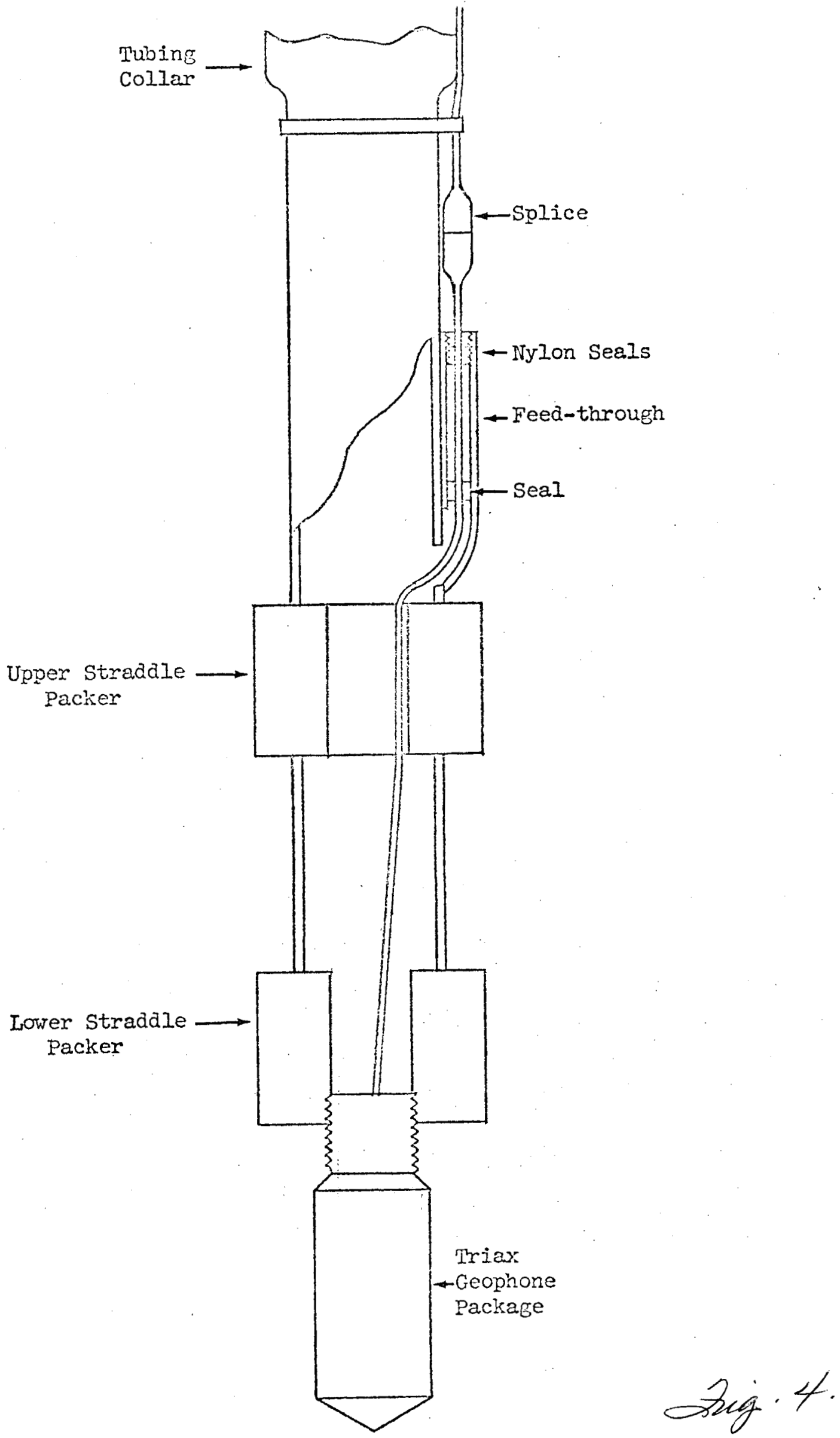




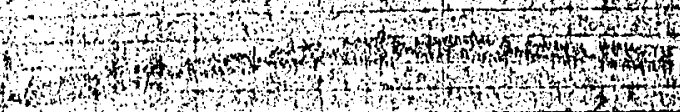

\section{CHAM 13 SURFACERESS}

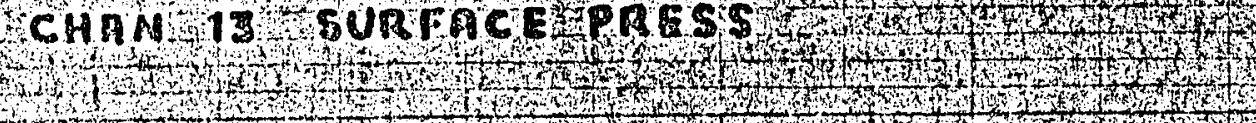

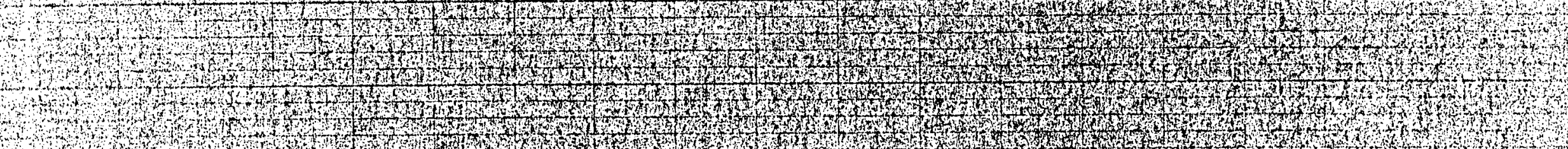

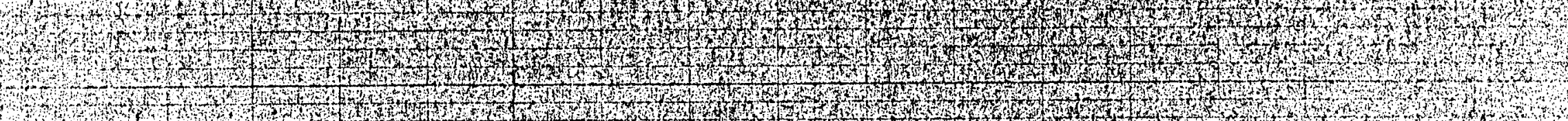

\begin{tabular}{ll}
\hline 13 \\
\hline 1
\end{tabular}

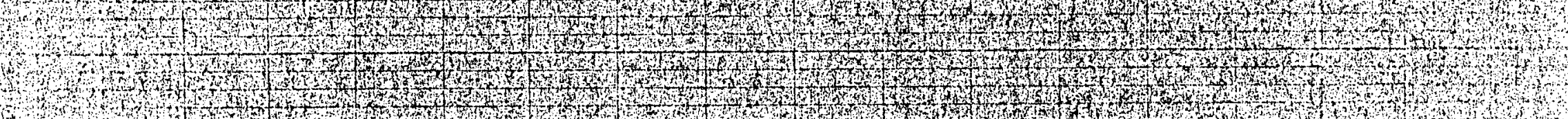

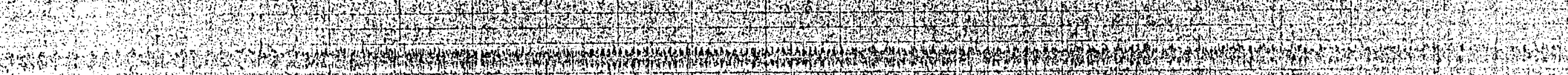

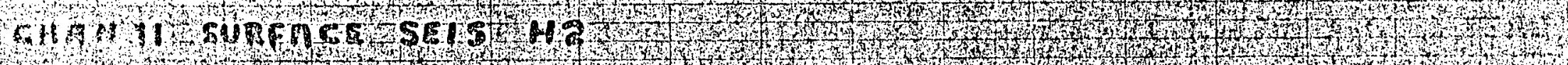

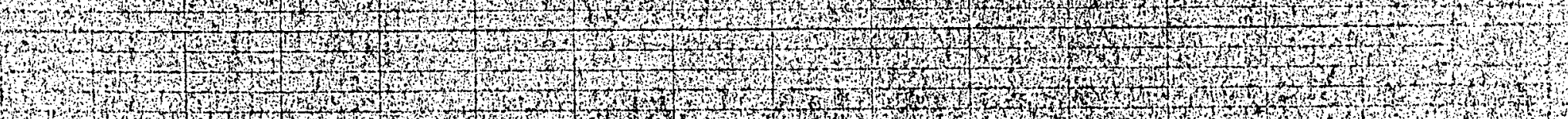

\begin{tabular}{l}
\hline 3 \\
\hline
\end{tabular}

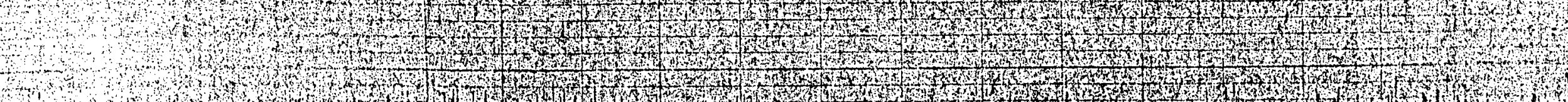

H.

man

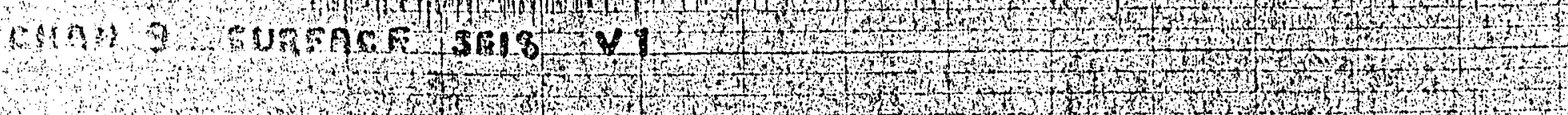
\begin{tabular}{l}
3 \\
\hline
\end{tabular} 
$3.28 .73 \quad 1 S T$ PUMP

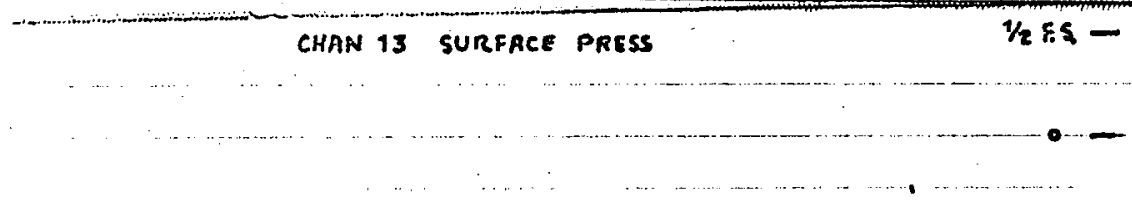

CHAN 11 SURFACE SEIS HZ

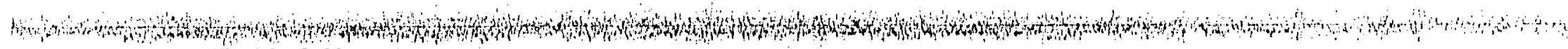
CHAN 9 SURFACE SEIS VI

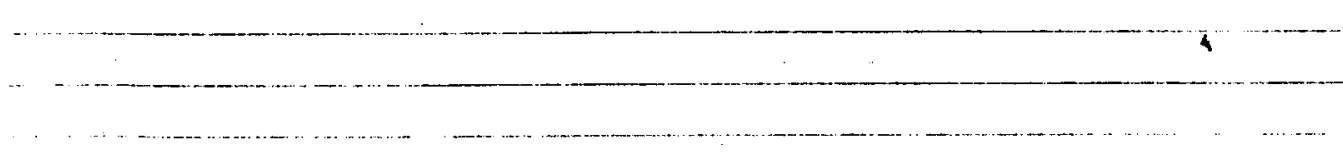

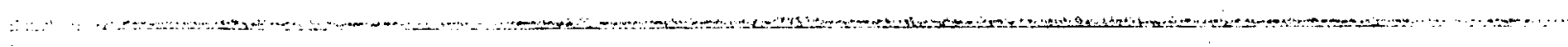

Fire. 6. Breakd own oressure กT-1 3-38.73 



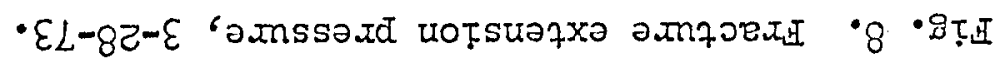

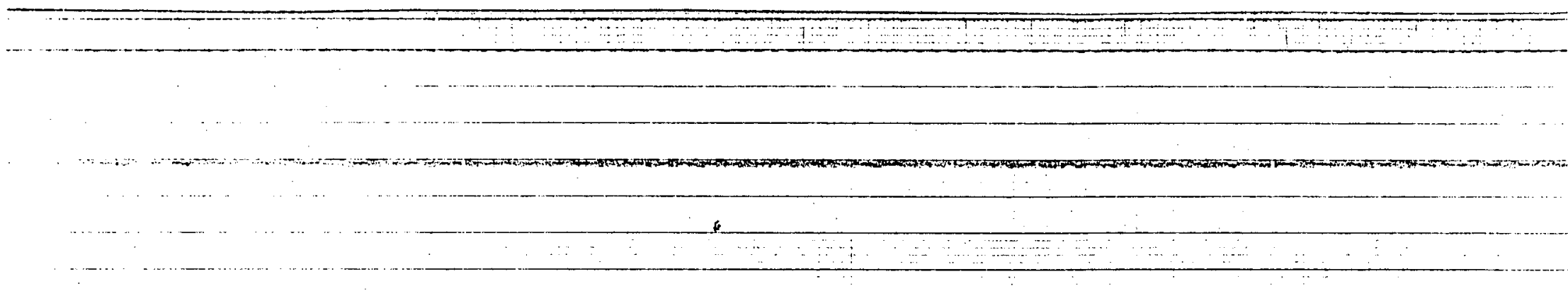

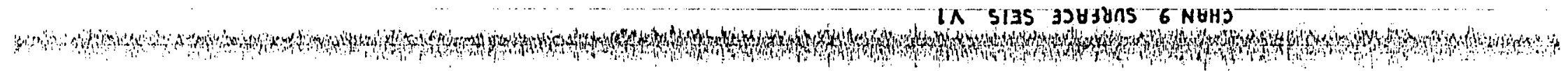

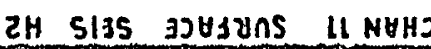

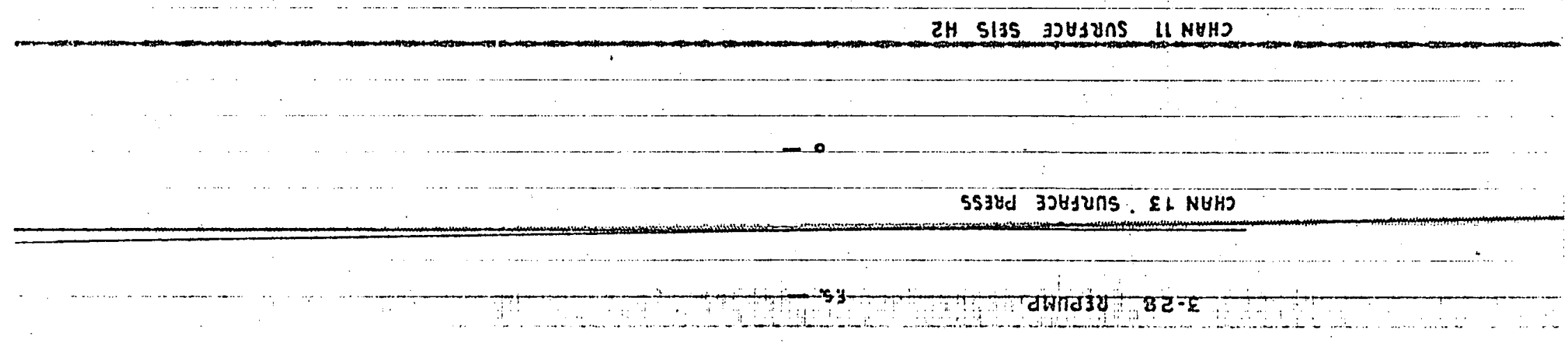









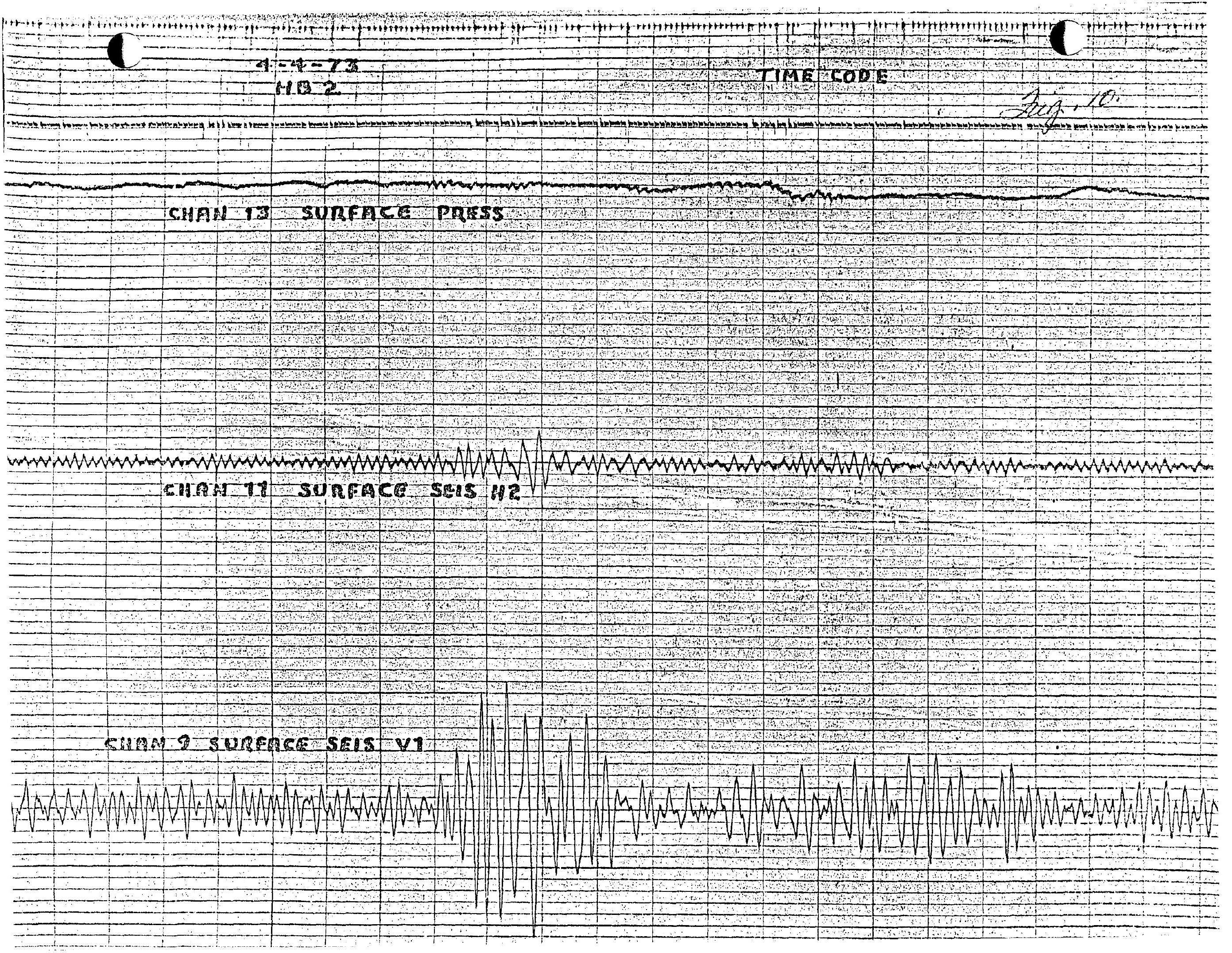




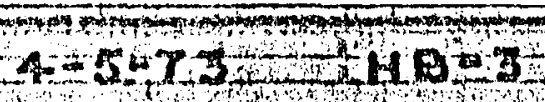


C

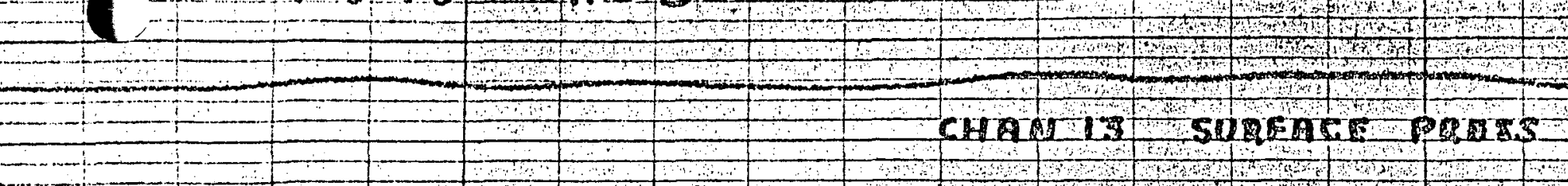

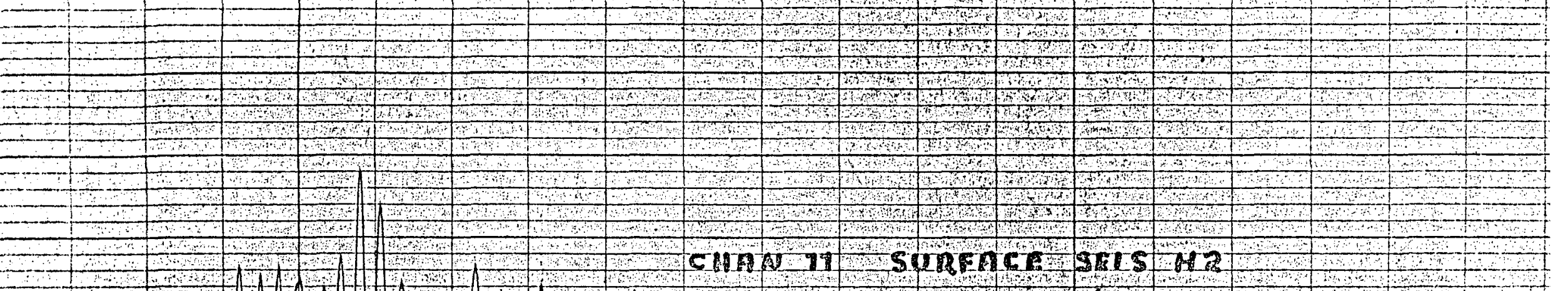

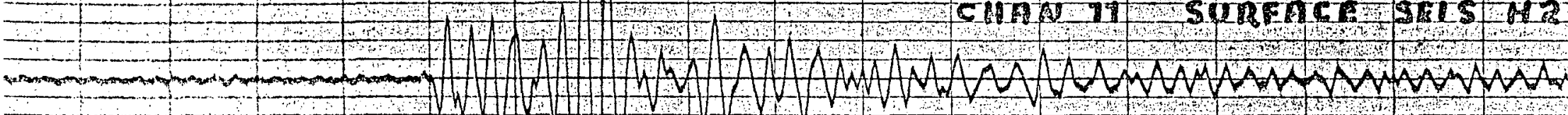

-

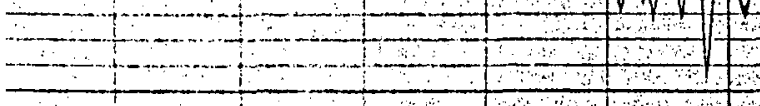




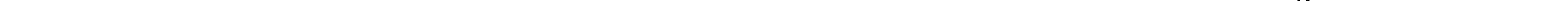

